\title{
Pleural effusion and multiple myeloma - more than meets the eye: A case report
}

\author{
ANA LUÍSA RAMOS ${ }^{1}$, MIGUEL TRINDADE ${ }^{2}$, ANDRÉ SANTOS PINTO ${ }^{3}$, \\ JOSÉ RICARDO BRANDÃO ${ }^{4}$, CLÁUDIA PEDROSA ${ }^{5}$ and ALEXANDRE PINTO ${ }^{6}$ \\ ${ }^{1}$ Pulmonology Department, Egas Moniz Hospital, 1349-019 Lisbon; \\ ${ }^{2}$ Medicine Department, Fernando Fonseca Hospital, 2720-276 Amadora; \\ ${ }^{3}$ Medicine Department, West Hospital Center-Torres Vedras, 2560-324 Torres Vedras; \\ Departments of ${ }^{4}$ Pathological Anatomy, ${ }^{5}$ Clinical Hematology and ${ }^{6}$ Intensive Care, \\ University Hospital Center of Porto, 4099-901 Porto, Portugal
}

Received February 4, 2021; Accepted August 13, 2021

DOI: $10.3892 / \mathrm{mco} .2021 .2401$

\begin{abstract}
Multiple myeloma (MM) accounts for $1 \%$ of all cancers. It consists of malignant proliferation of plasma cells, which is often associated with hypersecretion of a monoclonal protein. Pleural effusion (PE) in $\mathrm{MM}$ is not an uncommon finding, comprising about $6-14 \%$ of patients with MM. The most common causes of MM-associated PE are congestive heart failure, renal failure, parapneumonic effusion and amyloidosis. In $<1 \%$ of cases, the effusion is a direct result of MM, designated as myelomatous PE (MPE). MPE is usually a diagnosis of exclusion and carries a poor prognosis. Therefore, efforts should be made to optimally detect MPE. The present report describes an MPE associated with $\mathrm{IgG} / \lambda$ MM presenting as a septic shock and renal failure in which a rare diagnosis was made after excluding all other possible etiologies in a complex intensive care patient.
\end{abstract}

\section{Introduction}

Multiple myeloma (MM) accounts for $10 \%$ of all hematologic malignancies and approximately $1 \%$ of all cancers (1). It affects predominantly the elderly and consists of a malignant proliferation of plasma cells (PC). These malignant cells are mostly found inside the bone marrow but they can also be present in extramedullary disease (ED) $(1,2)$. Plasma cells are responsible for hypersecretion of $\mathrm{M}$ protein, which represents defective immunoglobulin, and lead to a well-known association of symptoms named CRAB-hypercalcemia, renal failure, anemia and bone lytic lesions $(2,3)$.

Correspondence to: Dr Ana Luísa Ramos, Pulmonology Department, Egas Moniz Hospital, 126 Junqueira Street, 1349-019 Lisbon, Portugal

E-mail: analuisarces@gmail.com

Key words: multiple myeloma, myelomatous pleural effusion, diagnosis, flow cytometry, survival
Pleural effusion (PE) in multiple myeloma is not an uncommon finding, comprising about $6-14 \%$ of $\mathrm{MM}$ patients (4-6). The most common causes of MM associated $\mathrm{PE}$ are congestive heart failure, renal failure with or without nephrotic syndrome, parapneumonic effusion and amyloidosis. Other causes can be hypoalbuminemia, pulmonary embolism, secondary neoplasm and lymphatic obstruction with chylothorax. In less than $1 \%$ of cases, the effusion is a direct result of MM, designated as myelomatous pleural effusion (MPE) (7). Several mechanisms have been proposed for the pathogenesis of pleural effusion in MM. They mostly originate from adjacent skeletal or parenchymal tumors such as vertebral or pulmonary plasmacytomas, direct pleural invasion by tumor nodules (hematogenous dissemination) and mediastinal lymph node infiltration with lymphatic blockage. The extramedullary spread can be triggered by an invasive procedure (surgery or catheter insertion) or by a bone fracture (8-11).

Rodriguez et al (12) established the diagnostic criteria for MPE: Pleural fluid electrophoresis with monoclonal protein plus atypical plasma cells in the pleural fluid plus histological confirmation by pleural biopsy. Eighty percent of MPEs are associated with IgA MM (13) and present late in the course of the disease, carrying a poor prognosis and a life expectancy of about 4 months. There is no distinct therapy for the MPE and in some cases, palliative pleurodesis is the only treatment possible (14).

Here we report an MPE associated with $\mathrm{IgG} / \lambda \mathrm{MM}$ presenting as a septic shock and renal failure requiring hemodialysis in which a rare diagnosis was made after excluding all other possible etiologies in a complex intensive care patient.

\section{Case report}

The authors describe the case of a 79-year-old white woman, with $\mathrm{IgG} / \lambda \mathrm{MM}$, hypertension, type 2 diabetes mellitus, dyslipidemia and hyperuricemia. MM was diagnosed two months prior admission (Fig. 1). At diagnosis, the patient had an increase in total serum proteins $(14.77 \mathrm{~g} / \mathrm{dl})$ at the 
expense of an increase in $\gamma$-globulins $(8.8 \mathrm{~g} / \mathrm{dl} ; 59.40 \%)$. The measurement of serum immunoglobulins revealed an increase in the concentration of heavy $\mathrm{IgG}$ chains $(10,706.0 \mathrm{mg} / \mathrm{dl})$ and free $\lambda$ light chains $(2,720 \mathrm{mg} / \mathrm{dl})$. Immunofixation revealed the presence of an $\mathrm{IgG} / \lambda$ monoclonal gammopathy. At that time, medullary aspirate was performed, which was very hypocellular $\left(10.0 \times 10^{3} / \mu 1\right)$, according to flow cytometry $10 \%$ of the cells were plasmocytes with abnormal phenotypic

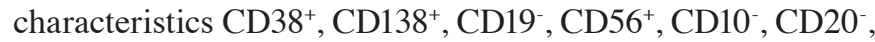
CD117, CD45.

She presented anemia and lytic bone lesions in the skull. She started on oral melphalan and prednisolone. She was classified as an Eastern Cooperative Oncology Group (ECOG) Performance Status 1.

She was admitted to the emergency department in March 2020 with symptoms of fatigue, severe bone pain, and diarrhea. On admission, she presented with hemodynamic instability, oliguric, and requiring oxygen through a face mask. Physical examination revealed a decrease in breath sounds throughout the right hemithorax. Complete blood count revealed anemia $(\mathrm{Hb} 8.1 \mathrm{~g} / \mathrm{dl})$, leukocytosis $\left(12.7 \times 10^{9} / 1\right)$, neutrophilia $\left(11.3 \times 10^{9} / 1\right)$ and thrombocytopenia $\left(35 \times 10^{9} / 1\right)$. Chemistry panel revealed C-reactive protein $352.4 \mathrm{mg} / 1$, creatinine $3.96 \mathrm{mg} / \mathrm{dl}$ and albumin of $1.83 \mathrm{~g} / \mathrm{dl}$. Arterial blood gas analysis showed a type 1 respiratory insufficiency and hyperlactacidemia $(4.9 \mathrm{mg} / \mathrm{dl})$. The chest X-ray showed a bilateral pleural effusion (Fig. 2). Diagnostic thoracentesis was performed and the pleural fluid was compatible with an exudate using Light's criteria (15).

She deteriorated and was admitted to the intensive care unit for septic shock with multiorgan failure: renal, hematological, neurological, cardiovascular and respiratory failures. Blood and urine samples were withdrawn and sent for microbiological analysis and she was started on broad-spectrum antibiotics. Due to hypervolemia and acute renal failure, she was put on sustained low-efficiency daily diafiltration (SLEDD) aimed for a negative fluid balance. Despite all measures instituted, she continued to deteriorate with dyspnea, tachypnea, desaturation, and aggravated pleural effusion (Fig. 3).

The infectious etiology had been assumed as a most likely cause for the pleural effusion. Despite diminishing inflammatory parameters, pleural effusion enlarged causing additional respiratory compromise. Other PE causes were also addressed like renal failure and hypoalbuminemia. A detailed systematic approach to investigate the etiology of this pleural effusion was then undertaken.

Therapeutic thoracentesis was performed and 2,650 ml of serosanguineous fluid was removed (Fig. 4). The pleural fluid analysis showed $\mathrm{pH} 7.9$, adenosine deaminase $31.7 \mathrm{U} / 1$, and glucose $88 \mathrm{mg} / \mathrm{dl}$, proteins $3.5 \mathrm{~g} / \mathrm{dl}$, and LDH 618U/1. The ratio between pleural and serum LDH was indicative of exudative pleural effusion. Protein electrophoresis of pleural fluid showed a monoclonal $\gamma$-globulin spike $(1.2 \mathrm{~g} / \mathrm{dl}$, 34,2\%) (Fig. 5).

Flow cytometry showed $89 \%$ of abnormal PCs positive for CD38 (low, decreased intensity comparatively to normal PC), CD138, CD56 and CD117, and negative for CD10, CD19, CD20 and CD45. Normal PC phenotype, for comparison: CD45+low, $\mathrm{CD} 38^{\text {+high }}, \mathrm{CD}^{\text {+l }} 38^{+}, \mathrm{CD} 19^{+}, \mathrm{CD} 20^{-}$, $\mathrm{CD}^{\circ}{ }^{\circ}, \mathrm{CD}_{117^{-}}(16)$. The pleural fluid cells were stained with

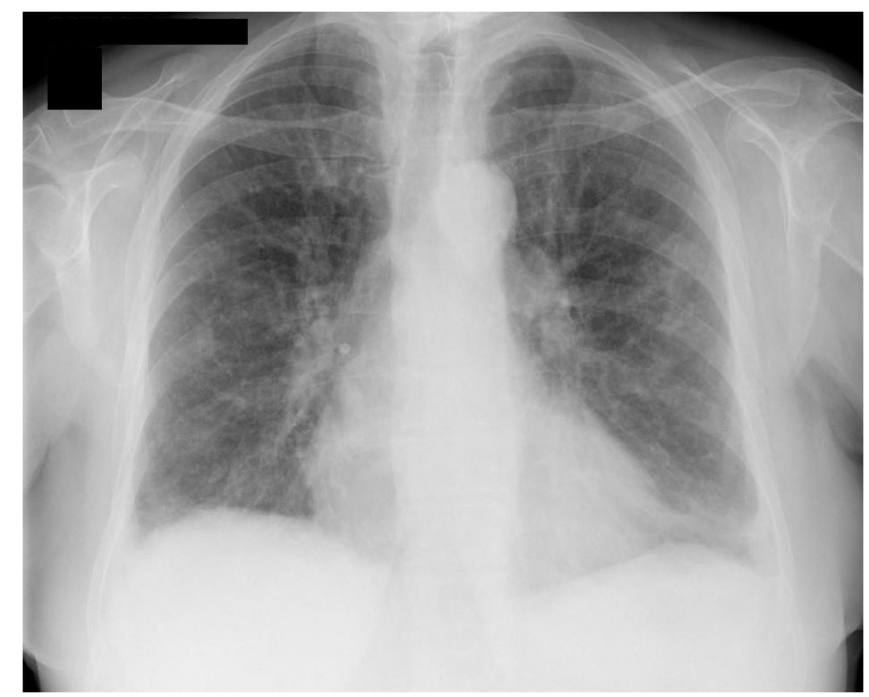

Figure 1. Chest X-ray at the moment of the diagnosis of multiple myeloma. No evidence of pleural effusion (January 2020).

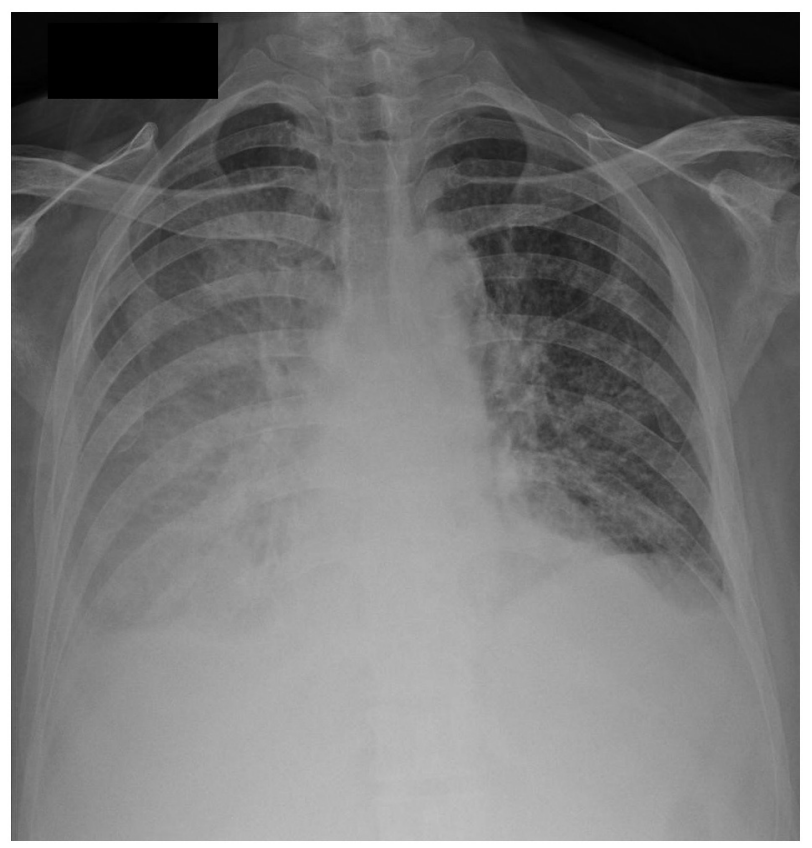

Figure 2. Chest X-ray on hospital admission. Right pleural effusion (March 2020).

an 8-color panel of fluorochrome-conjugated monoclonal antibodies specific for the aforementioned molecules, processed with BD FACS ${ }^{\mathrm{TM}}$ lysing solution according to the manufacturer's instructions (Becton Dickinson) and acquired using a BD FACSCanto ${ }^{\mathrm{TM}}$ II flow cytometer (Becton Dickinson). Data generated as FCS files were analyzed using the Infinicyt ${ }^{\mathrm{TM}}$ software (Cytognos). FSC and SSC were captured on a linear scale (250 channels), and SSC was represented with a mathematical transformation to expand the values of the lower part of the scale for a better visualization of the populations. For fluorescence parameters, a logarithmic amplification was used, with logical transformation, allowing for a resolution of 262 144 channels ( $\sim 5.42$ decades) (Fig. 6). 


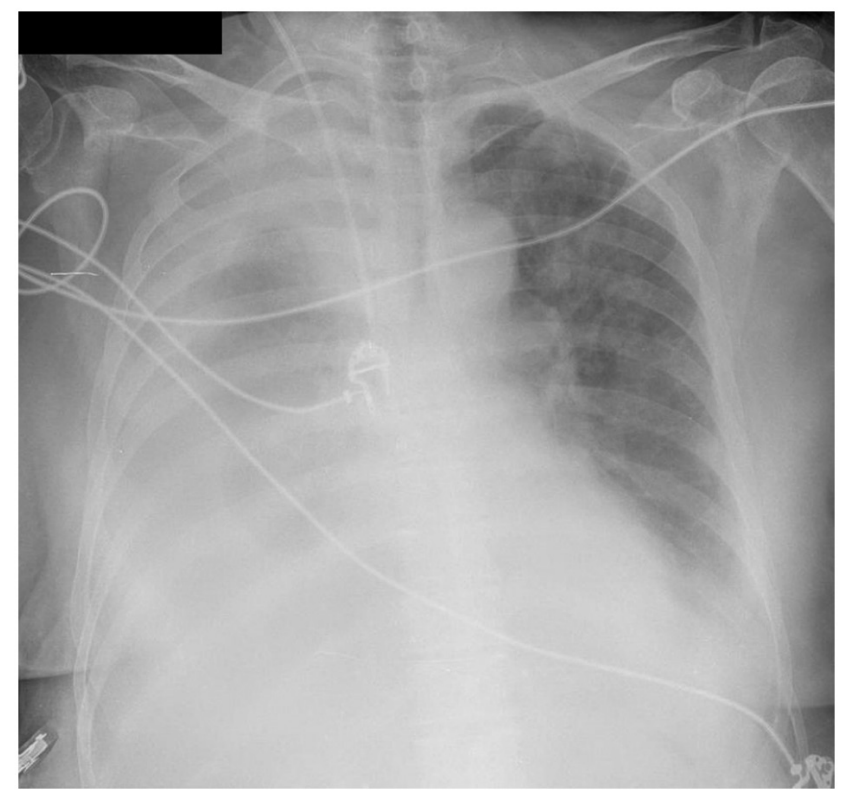

Figure 3. Chest X-ray at 5 days after admission. Large volume right pleural effusion.

The cytological exam and immunocytochemical study proved to be compatible with a plasma cell proliferation (Figs. 7 and 8). Bacteriological exam of the pleural fluid revealed a multi-resistant Escherichia coli. Histological confirmation on pleural biopsies, was deemed as presenting with no benefit for the patient and was not performed. A diagnosis of myelomatous pleural effusion with bacterial overinfection was made.

Although respiratory insufficiency had improved, the patient still degraded and the conditions to start MM induction therapy were not met. Due to the poor prognosis of extramedullary disease, particularly involving MPE, and the deterioration of performance status of the patient, it was decided to withdraw therapeutic measures and begin palliative care. The patient died 10 days after hospital admission.

\section{Discussion}

In the past few years, the incidence of EMD has risen, probably due to the greater sensitivity of imaging tests but also due to the increased survival of patients as a result of advances in the therapeutic strategy of MM $(17,18)$. Evidence of extramedullary disease is a clear marker of poor prognosis and the MPE is no exception. Even with aggressive therapy, MPE has a progression-free survival and overall survival of fewer than 4 months. The prognosis is even worst when the mechanism involved in the progression of the disease is hematogenous spread $(17,19)$.

The patient had an ongoing infectious process, with renal and cardiovascular failure combined with hypoalbuminemia, so she had multiple factors for pleural effusion and they were much more prevalent than MPE. There were no pulmonary or bone lesions suggestive of plasmacytomas on chest X-ray. The initial approach to pleural effusion was incomplete, probably due to a lack of clinical suspicion, contributing to the delay in diagnosis.

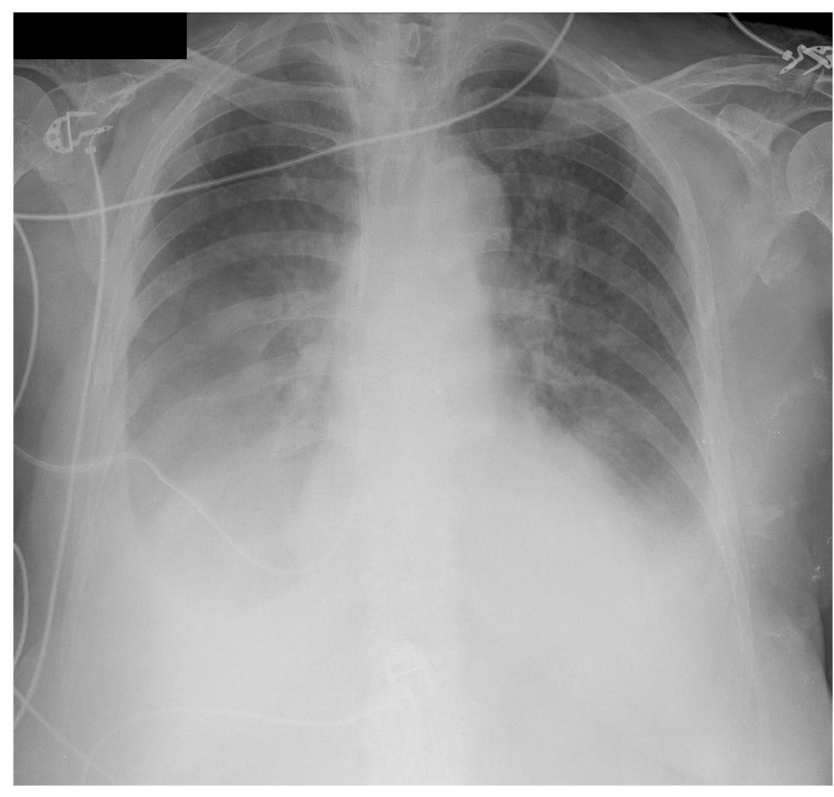

Figure 4. Chest X-ray after therapeutic thoracentesis.

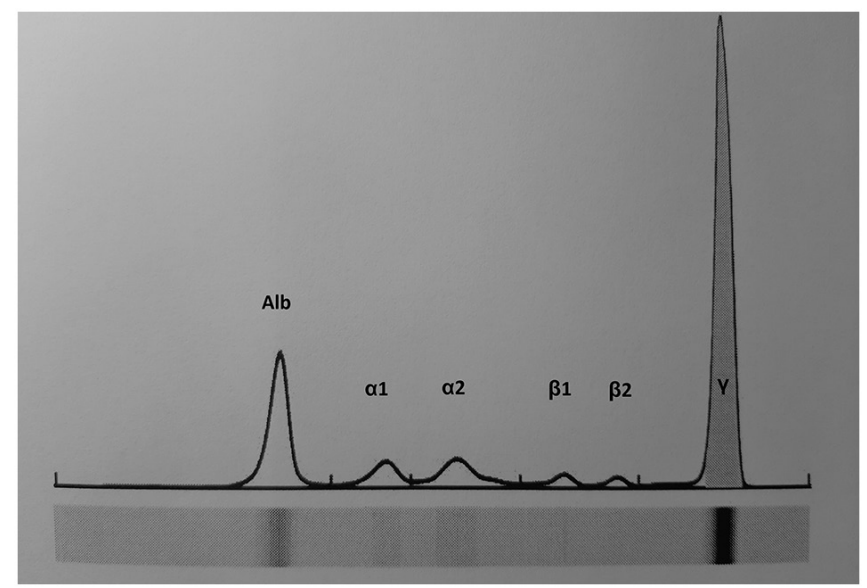

Figure 5. Pleural fluid capillary electrophoresis showing a $\gamma$-globulin spike (Alb, 36.7\%; $\alpha 1,5.7 \% ; \alpha 2,10.4 \% ; \beta$ globulina, $11.0 \% ; \gamma, 34.2 \%$; pico monoclonal, 33.4\%). Alb, albumina; $\alpha 1, \alpha 1$ globulinal; $\alpha 2, \alpha 2$ globulina; $\beta 1$, $\beta 1$ globulina; $\beta 2, \beta 2$ globulina; $\gamma, \gamma$ globulina.

Despite the existence of specific criteria, diagnosing MPE remains a challenge. Pleural cytology has a diagnosis rate for malignancy of around $60 \%$ (20). Blind pleural biopsy is a procedure with associated risks and less attractive as a diagnostic tool, since MPE affects the pleura irregularly. Nevertheless, pleural fluid cytology or pleural biopsy provides the diagnosis of MPE in approximately half of these patients $(21,22)$.

Flow cytometry of pleural fluid is an excellent complementary diagnostic method to the traditional strategy. It is a fast, very sensitive and effective technique that allows not only for plasma cell quantification but also for the identification of phenotypically abnormal malignant plasma cells, thereby improving the diagnosis of MPE. Its use is particularly relevant in complementing the cytological assessment of serous fluids that lack a predominance of plasma cells, or where these cells lack definitive malignant 

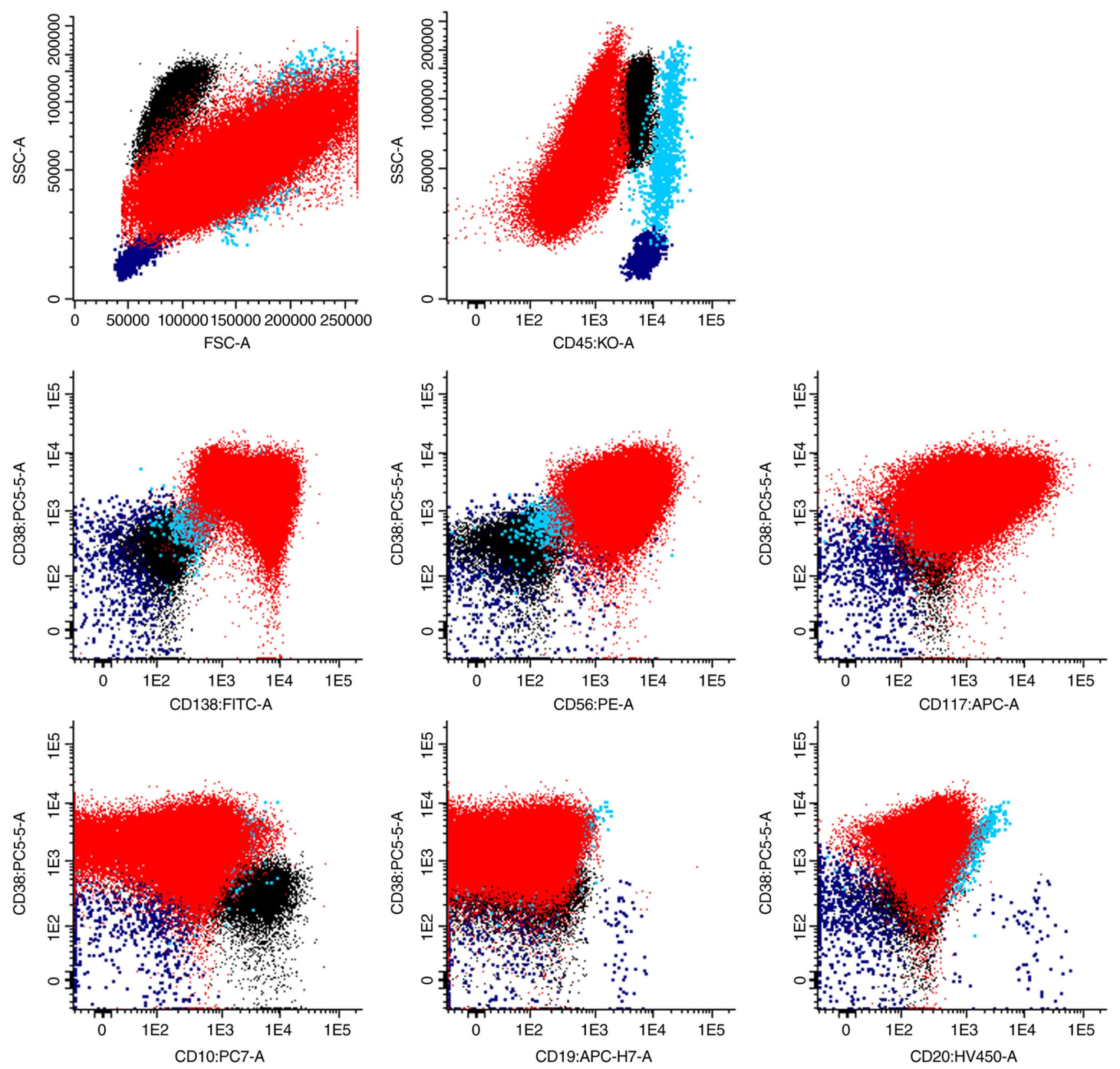

Figure 6. Flow cytometry dot plots showing $89 \%$ of abnormal PCs in the pleural fluid (red dots), together with neutrophils (black dots), lymphocytes (dark blue dots) and monocytes/macrophages (blue dots). The abnormal PCs were positive for CD38 (low, decreased intensity comparatively to normal PC), CD138, CD56 and CD117, and negative for CD10, CD19, CD20 and CD45. Normal PC phenotype, for comparison: CD45 ${ }^{\text {tlow }}, \mathrm{CD} 38^{+ \text {thigh }}, \mathrm{CD} 138^{+}, \mathrm{CD} 19^{+}, \mathrm{CD} 20^{-}, \mathrm{CD} 56^{-}$, CD117. APC, allophycocyanin; APC-H7, allophycocyanin-H7; FITC, fluorescein isothiocyanate; FSC, forward scatter; KO, chrome orange; PCs, plasma cells; PC5.5, phycoerythrin-cyanine 5.5; PC7, phycoerythrin-cyanine 7; PE, phycoerythrin; SSC, side scatter.

morphological features (23). These characteristics add important value to pleural fluid differential diagnosis. Thus, the authors aim to warn of the need to review the MPE diagnostic criteria in light of the current knowledge and available diagnostic tests.

Only a proper diagnosis will allow early intervention. And despite the absence of aimed therapy for this high-risk group of patients, the use of drugs, namely proteasome inhibitors, (intravenous or intrapleural) has brought some hope in the last few years (24). More clinical trials are still needed in the future to better define the correct strategy for these patients.

In conclusion, pleural effusion in patients with $\mathrm{MM}$ is a heterogeneous entity that can arise from a varied number of etiologies that require different treatments. A proper and complete examination is essential in the diagnosis of MPE due to the therapeutic and prognostic implications, including cytological examination, protein electrophoresis with immunofixation, flow cytometry and ultimately pleural biopsy.

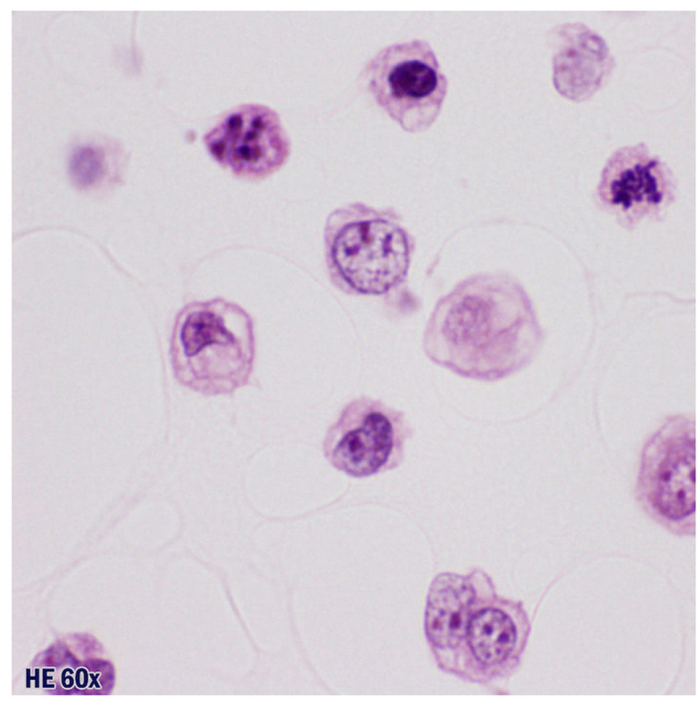

Figure 7. Cytological analysis showing some cells with plasmablastic morphology, a mitotic figure and an apoptotic cell (hematoxylin and eosin coloration; magnification, x60). 


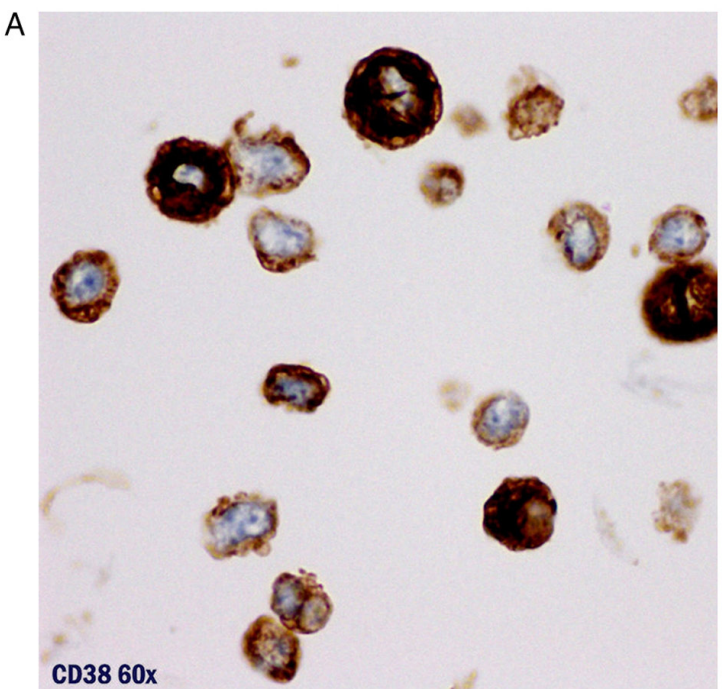

B

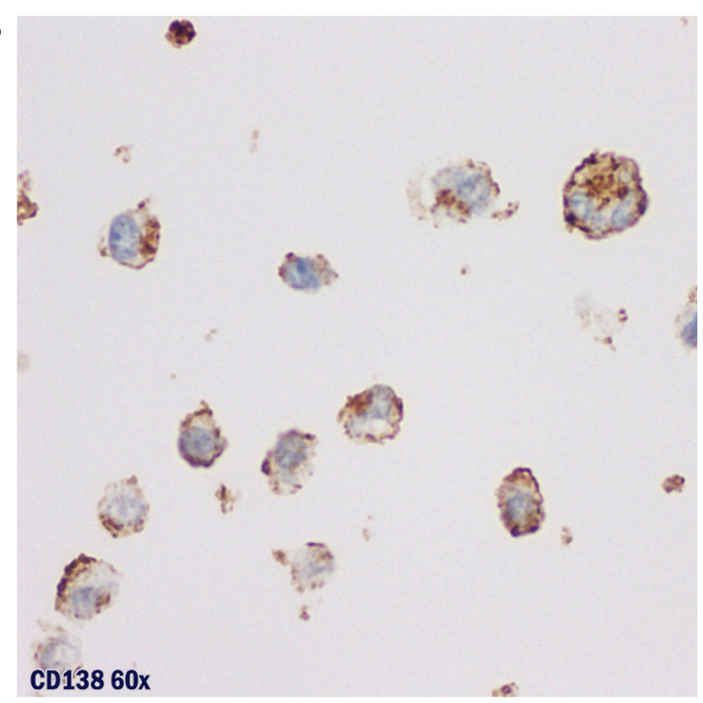

Figure 8. Immunohistochemical examination of plasma cells via staining of the cell markers (A) CD38 (magnification, x60) and (B) CD138 (magnification, x60).

\section{Acknowledgements}

The authors would like to thank Dr Luís Ramos Silva (Department of Clinical Hematology, Hospital Center of São João, 4200-319 Porto, Portugal) and Professor Margarida Lima (Department of Clinical Hematology-responsible for the cytometry and genetics laboratories, University Hospital Center of Porto, 4099-901 Porto, Portugal) for intellectual and technical assistance, and helping in the writing of the manuscript.

\section{Funding}

No funding was received.

\section{Availability of data and materials}

The datasets used and/or analyzed during the current study are available from the corresponding author on reasonable request.

\section{Authors' contributions}

ALR, MT and ASP contributed to the planning, conduct, reporting, conception, design and acquisition of data, and drafting the manuscript. JRB, CP and AP contributed to planning, conduct, reporting, reporting, conception, design, and acquisition of data and revision of the article. ALR, MT and ASP confirm the authenticity of all the raw data. All authors read and approved the final manuscript.

\section{Ethics approval and consent to participate}

The present study involving a human subject was in accordance with the Declaration of Helsinki 1975 as revised in 2000 and was approved by the Ethical Committee of University Hospital Center of Porto, University of Porto (Porto, Portugal).

\section{Patient consent for publication}

The requirement for consent was waived and the study was approved by the Ethical Committee of University Hospital Center of Porto, University of Porto (Porto, Portugal).

\section{Competing interests}

The authors declare that they have no competing interests.

\section{References}

1. ShortK, Rajkumar S,Larson D, Buadi F,Hayman S,Dispenzieri A, Gertz M, Kumar S, Mikhael J, Roy V, et al: Incidence of extramedullary disease in patients with multiple myeloma in the era of novel therapy, and the activity of pomalidomide on extramedullary myeloma. Leukemia 25: 906-908, 2011.

2. Swerdlow SH, Campo E, Pileri SA, Harris NL, Stein H, Siebert R, Advani R, Ghielmini M, Salles GA, Zelenetz AD and Jaffe ES: The 2016 revision of the world health organization classification of lymphoid neoplasms. Blood 127: 2375-2390, 2017.

3. Kyle RA and Rajkumar SV: Multiple myeloma. N Engl J Med 351: 1860-73, 2004.

4. Byun JM, Kim KH, Choi IS, Park JH, Kim JS, Shin DY, Koh Y, Kim I, Yoon SS and Lim HJ: Pleural effusion in multiple myeloma: Characteristics and practice patterns. Acta Haematol 138: 69-76, 2017.

5. Wang Z, Xia G, Lan L, Liu F, Wang Y, Liu B, Ding Y, Dai L and Zhang Y: Pleural effusion in multiple myeloma. Intern Med 55: 339-345, 2016.

6. Kintzer J, Rosenow EC III and Kyle RA: Thoracic and pulmonary abnormalities in multiple myeloma. A review of 958 Cases. Arch Intern Med 138: 727-730, 1978

7. Oudart JB, Maquart FX, Semouma O, Lauer M, Arthuis-Demoulin P and Ramont L: Pleural effusion in a patient with multiple myeloma. Clin Chem 58: 672-674, 2012.

8. Bladé J, de Larrea CF, Rosiñol L, Cibeira MT, Jiménez R and Powles R: Soft-tissue plasmacytomas in multiple myeloma: Incidence, mechanisms of extramedullary spread, and treatment approach. J Clin Oncol 29: 3805-3812, 2011.

9. Weinstock $M$ and Ghobrial IM: Extramedullary multiple myeloma. Leuk Lymphoma 54: 1135-1141, 2013.

10. De Larrea CF, Rosiñol L, Cibeira MT, Rozman M, Rovira M and Bladé J: Extensive soft-tissue involvement by plasmablastic myeloma arising from displaced humeral fractures. Eur J Haematol 85: 448-451, 2010.

11. Alexandrakis MG, Passam FH, Kyriakou DS and Bouros D: Pleural effusions in hematologic malignancies. Chest 125: 1546-1555, 2004

12. Rodriguez J, Pereira A, Martínez JC,Conde J and Pujol E: Pleural effusion in multiple myeloma. Chest 105: 622-624, 1994.

13. Shirdel A, Attaran D, Ghobadi H and Ghiasi T: Myelomatous pleural effusion. Tanaffos 6: 68-72, 2007. 
14. Iqbal N, Tariq MU, Shaikh MU and Majid H: Pleural effusion as a manifestation of multiple myeloma. BMJ Case Rep 12: bcr2016215433, 2016.

15. Light RW: The light criteria: The beginning and why they are useful 40 years later. Clin Chest Med 34: 21-26, 2013.

16. Bataiile R, Jégo G, Robillard N, Barillé-Nion D, Harousseau JL, Moreau P, Amiot M and Pellat-Deceunynck C: The phenotype of normal, reactive and malignant plasma cells. Identification of 'many and multiple myelomas' and of new targets for myeloma therapy. Haematologica 91: 1234-1240, 2006.

17. Touzeau $\mathrm{C}$ and Moreau P: How I treat extramedullary myeloma. Blood 127: 971-976, 2016.

18. Varga C, Xie W, Laubach J, Ghobrial IM, O'Donnell EK, Weinstock M, Paba-Prada C, Warren D, Maglio ME, Schlossman R, et al: Development of extramedullary myeloma in the era of novel agents: No evidence of increased risk with lenalidomide-bortezomib combinations. Br J Haematol 169: 843-850, 2015

19. Usmani SZ, Heuck C, Mitchell A, Szymonifka J, Nair B, Hoering A, Alsayed Y, Waheed S, Haider S, Restrepo A, et al: Extramedullary disease portends poor prognosis in multiple myeloma and is over-represented in high-risk disease even in the era of novel agents. Haematologica 97: 1761-1767, 2012.

20. Havelock T, Teoh R, Laws D and Gleeson F; BTS Pleural Disease Guideline Group: Pleural procedures and thoracic ultrasound: British thoracic society pleural disease guideline 2010. Thorax 65 (Suppl 2): ii61-ii76, 2010.
21. Kamble R, Wilson CS, Fassas A, Desikan R, Siegel DS, Tricot G, Anderson P, Sawyer J, Anaissie E and Barlogie B: Malignant pleural effusion of multiple myeloma: Prognostic factors and outcome. Leuk Lymphoma 46: 1137-1142, 2005.

22. Kim YJ, Kim SJ, Min K, Kim HY, Kim HJ, Lee YK and Zang DY: Multiple myeloma with myelomatous pleural effusion: A case report and review of the literature. Acta Haematol 120: 108-111, 2008.

23. Palmer HE, Wilson CS and Bardales RH: Cytology and flow cytometry of malignant effusions of multiple myeloma. Diagn Cytopathol 22: 147-151, 2000.

24. Iannitto E, Minardi V and Tripodo C: Use of intrapleural bortezomib in myelomatous pleural effusion. Br J Haematol 139: 621-622, 2007.

This work is licensed under a Creative Commons Attribution-NonCommercial-NoDerivatives 4.0 International (CC BY-NC-ND 4.0) License. 